Article

\title{
Dimensions of Social Equality in Paid Parental Leave Policy Design: Comparing Australia and Japan
}

\author{
Gillian Whitehouse ${ }^{1, *}$ and Hideki Nakazato ${ }^{2}$ \\ ${ }^{1}$ School of Political Science and International Studies, The University of Queensland, St Lucia, QLD 4072, Australia; \\ E-Mail: g.whitehouse@uq.edu.au \\ 2 Department of Sociology, Faculty of Letters, Konan University, Kobe 658-0581, Japan; E-Mail: nakazato@konan-u.ac.jp \\ * Corresponding author
}

Submitted: 18 November 2020 | Accepted: 3 March 2021 | Published: 11 June 2021

\begin{abstract}
Paid parental leave policies in both Australia and Japan fit within Dobrotić and Blum's (2020) classification of a selective employment-based entitlement model, thus offering an extension of that category beyond Europe and illustrating the wide variation possible within it. In this article we develop indices for comparing employment-based parental leave policies on three dimensions of social equality: inclusion, gender equality and redistribution. This combination offers an extension of classificatory schemes for parental leave policies and a broader basis for comparative analysis. We compare Australia and Japan on these indices and present a qualitative exploration of the origins and implications of their similarities and differences. The analysis draws attention to tensions between the three indices, illustrating intersecting and conflicting influences on the potential for paid parental leave entitlements to contribute to the amelioration of social inequalities. Overall, the comparison highlights drivers of difference within employment-based entitlement systems and underlines the need for complementary measures to advance egalitarian outcomes.
\end{abstract}

\section{Keywords}

Australia; gender equality; inclusion; Japan; leave policy design; paid parental leave; redistribution; social equality

\section{Issue}

This article is part of the issue "The Inclusiveness of Social Rights: The Case of Parental Leave Policies" edited by Sonja Blum (University of Hagen, Germany) and Ivana Dobrotić (University of Oxford, UK / University of Zagreb, Croatia).

(C) 2021 by the authors; licensee Cogitatio (Lisbon, Portugal). This article is licensed under a Creative Commons Attribution 4.0 International License (CC BY).

\section{Introduction}

Social inequalities associated with parental leave policies continue to comprise a major theme in leave policy research, with divisions between the "parental-leave rich and parental-leave poor" (McKay, Mathieu, \& Doucet, 2016) potentially widening within and between countries. This is particularly the case for employment-based entitlements in the context of widespread fragmentation of work and the expansion of non-standard and insecure forms of employment in what Palier (2018, p. 247) depicts as "a long-term dualisation trajectory." Such trends clearly have the capacity to narrow the reach of employment entitlements such as paid parental leave in ways that exacerbate social inequalities (see, e.g., Howcroft \& Rubery, 2019; Whitehouse \& Brady, 2019). In addition to concerns about access, it has long been recognised that parental leave policies may reinforce rather than ameliorate gendered divisions of paid and unpaid labour and adversely affect women's employment trajectories (for an overview see Hegewisch \& Gornick, 2011). A less frequently noted issue is that income inequality may also be consolidated among users of parental leave entitlements depending on the extent to which the distribution of payments is 'regressive' (i.e., delivering greater benefits to higher-earning parents) rather than 'progressive' (i.e., relatively advantageous to the lower paid). This adds to the impact of unequal 
access, which has been shown to disproportionately benefit the social reproduction of higher social strata (see, e.g., Ghysels \& Van Lancker, 2011; Mckay et al., 2016; O'Brien, 2009).

In this article we compare employment-based paid parental leave provisions in Australia and Japan, assessing their implications for these three dimensions of social equality, which we label inclusion, gender equality and redistribution. The focus is thus on policy design rather than uptake and impact, for which there are insufficiently detailed cross-nationally comparable statistics. Our comparative analysis of social equality in policy design nevertheless offers contributions at two levels, first in extending classificatory schemes for cross-national comparison of parental leave policies and, second, in highlighting contrasting possibilities in practice through a comparison of Australia and Japan. As non-European countries that fall into the same broad parental-leave entitlement type in Dobrotić and Blum's (2020, p. 593) 2×2 matrix, both having primarily employment-based entitlement principles and selective rather than universal eligibility criteria, Australia and Japan illustrate the wide variation possible within this category, raising questions over the origins and implications of their policy differences. These are explored with the goal of extending understanding of the complexities of designing policy for social objectives within employment-based systems and the barriers that stand in the way of egalitarian outcomes.

In the following section we outline our framework for analysis, explaining our methodological approach and the indices we have constructed to represent the three dimensions of social equality. We present our comparative analysis of Australia and Japan in the subsequent section, identifying and interrogating differences in their performance. In conclusion, we reflect on the drivers of variations within and between these employmentbased entitlement models, the contradictions they illustrate between our three indices, and the implications for future policy directions.

\section{A Framework for Analysis}

Cross-national comparison offers insights into the variety of policy possibilities and deeper understandings of extent to which national contexts shape policy framings and potential future directions. It has been widely applied in research on parental leave policy, informed by classifications ranging from Esping-Andersen's (1990) liberal, conservative and social democratic welfare regimes, through critical extensions of this typology in gendered family models and care regimes based on notions of (de)familialisation and maternalism (e.g., Crompton, 1999; Leitner, 2003; Lewis, 2001; Mathieu, 2016), to the development of classifications to represent the generosity and gender egalitarianism of parental leave policy provisions (e.g., Blofield \& Martínez Franzoni, 2015; Castro-García \& Pazod-Moran, 2016; Ciccia \& Verloo, 2012; Dearing, 2016; Gornick \& Meyers, 2003, 2008;
Javornik, 2014; Ray, Gornick, \& Schmitt, 2010; Smith \& Williams, 2007). More recently, Dobrotić and Blum (2020) have turned the focus explicitly to access to parental leave policies rather than measures of generosity in duration and payment, overlaying this with a gender dimension to provide an important addition to conceptualisations of social equality in policy design.

Our framework for comparing the social equality features of employment-based paid parental leave policies draws directly on Dobrotić and Blum's (2020, p. 599) eligibility index for a measure of 'inclusion.' However, unlike these authors, who address access to social rights more broadly, our focus is narrowly on employmentbased systems and their capacity to support our three separate dimensions of social equality. Hence, we use the employment-based, but not the citizenship-based, component of their eligibility index. Our second index, gender-equality, amalgamates features from the extensive comparative literature on this topic, while our third index, 'redistribution,' requires development from basic principles. The indices, which we outline below, are conceptualised as equally important dimensions of social equality that could potentially require trade-offs in practice. Cross-national analysis provides a lens through which to assess not only the extent of, and reasons for, differences on the indices, but also how policy designs might balance or exacerbate tensions between them.

Although the indices are designed to be applicable in broader cross-national comparisons, they are suitable for our two-country comparison, which applies them quantitatively only to illustrate major contrasts before turning to a qualitative exploration of differences and their implications. This methodological approach is compatible with a study based on two cases-a comparative design that allows for an appropriate balance between "descriptive depth and analytical challenge" (Tarrow, 2010, p. 246).

Table 1 sets out the criteria used to score the three indices, with inclusion, gender equality and redistribution in panels $A, B$ and $C$, respectively. In line with Dobrotić and Blum (2020) they are based solely on statutory provisions, on paid benefits rather than leave entitlements (which often have different eligibility and uptake provisions) and on 'parental' rather than gender-specific 'maternity' or 'paternity' entitlements. The selection of criteria and their weighting draws on prior research where available, but also involves judgements based on the application of theoretical and substantive knowledge (see also Dobrotić \& Blum, 2020, p. 596).

Drawn from Dobrotić and Blum (2020, p. 599), the inclusion index (Table 1, panel A) appropriately recognises concerns over inequalities in access due to variation in labour force attachment and security while omitting eligibility criteria that are not employment-related (such as access to benefits for the non-birth parent in same sex couples and for adoptive parents). The duration of employment (or insurance payments) required prior to accessing benefits is an important criterion in 
Table 1. Indices of inclusion, gender equality and redistribution in paid parental leave policy.

\begin{tabular}{|c|c|}
\hline Criteria & Score \\
\hline \multicolumn{2}{|l|}{ A: Inclusion ${ }^{a}$} \\
\hline \multicolumn{2}{|l|}{ Employment history } \\
\hline \multicolumn{2}{|l|}{ Employment period needed to qualify for benefits ${ }^{b}$} \\
\hline Without employment-based benefits & 0 \\
\hline$\geq 12$ months of employment & 1 \\
\hline 7-11 months of employment & 2 \\
\hline 3-6 months of employment & 3 \\
\hline$<3$ months of employment & 4 \\
\hline Employment contract before leave starts & 5 \\
\hline \multicolumn{2}{|l|}{ Employment period can be accumulated over longer time with interruptions } \\
\hline Interruptions not allowed & 0 \\
\hline Interruptions allowed; condition not applicable ${ }^{c}$ & 1 \\
\hline \multicolumn{2}{|l|}{ Employment period can be accumulated with different employers } \\
\hline Must be fulfilled with same employer & 0 \\
\hline Can be fulfilled with different employers; condition not applicable ${ }^{c}$ & 1 \\
\hline \multicolumn{2}{|l|}{ Different employment forms and sectors } \\
\hline \multicolumn{2}{|l|}{ Self-employed } \\
\hline Excluded & 0 \\
\hline Access to separate scheme, can be subject to stricter eligibility criteria & 1 \\
\hline Fully included in same scheme as employees & 2 \\
\hline \multicolumn{2}{|l|}{ Different professions/sectors } \\
\hline Some excluded & 0 \\
\hline Some have access to separate scheme, can be subject to stricter eligibility criteria & 1 \\
\hline All fully included under same scheme & 2 \\
\hline \multicolumn{2}{|l|}{ Marginally-employed } \\
\hline Certain level of earnings/working time is needed & 0 \\
\hline No conditions related to previous earnings/working time & 1 \\
\hline Maximum inclusion score & 12 \\
\hline
\end{tabular}

B: Gender equality

Gendered allocation and transferability of leave ${ }^{d}$

No entitlements for fathers

Entitlements primarily for mothers, transferable in special cases

Fully shared family, or fully transferable individual, entitlements

Family or individual entitlements with $<1 / 3$ non-transferable 3

Family or individual entitlements with $\geq 1 / 3$ non-transferable 4

Duration of well-paid non-transferable leave for fathers ${ }^{e}$

No well-paid non-transferable leave

$<1$ month well-paid

$\geq 1$ but $<3$ months well-paid

$\geq 3$ but $<6$ months well-paid

$\geq 6$ months well-paid

Duration of leave for mothers

$<14$ weeks, or $\geq 24$ months

$>14$ weeks and $<6$ months, or $>12$ and $<24$ months

6 to 12 months

Incentives for fathers' uptake

No

Yes

Flexibility permitted in usage

Breaks in usage (into two or more separate blocks) 0.5

Part-time usage in combination with part-time return to work 0.5

Maximum gender equality score 
Table 1. (Cont.) Indices of inclusion, gender equality and redistribution in paid parental leave policy.

\begin{tabular}{lr}
\hline Criteria & Score \\
\hline C: Redistribution & \\
Minimum payment & 0 \\
$\quad$ No set minimum & 1 \\
$\leq 20 \%$ average wage & 2 \\
$21-40 \%$ average wage & 3 \\
$41-60 \%$ average wage & 4 \\
$61-80 \%$ average wage & 5 \\
$>80 \%$ average wage & 0 \\
Maximum payment/cap & 1 \\
$>200 \%$ average wage (or no set maximum) & 2 \\
$181-200 \%$ average wage & 3 \\
$161-180 \%$ average wage & \\
$\leq 160 \%$ average wage & 0 \\
Payments taxable & 2 \\
$\quad$ No & 10 \\
Yes & \\
\hline Maximum redistribution score & \\
\hline
\end{tabular}

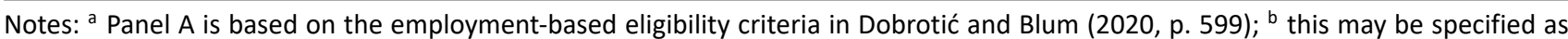
the period of contribution to employment insurance; ${ }^{c}$ not applicable if score is 5 for 'employment period needed'; ${ }^{d}$ this component of panel B draws on Dobrotić and Blum's (2020, pp. 598, 600) "gender dimension of leave policy design"; ' 'well-paid' is defined as $\geq 66 \%$ of earnings; for flat-rate and capped earnings-based payments, estimates are based on the flat-rate or earnings cap as a percentage of the average wage for full-time workers.

this context, with a qualifying period of 12 months or more widely seen as a restrictive barrier (Dobrotić \& Blum, 2020, p. 598). The following two items add to this lens, capturing-respectively-whether employment (or insurance payment) interruptions and changes of employer are permitted during the qualifying period (concessions often made incrementally as countries seek to expand the coverage of entitlements). The last three items capture exclusions. The self-employed are at risk of exclusion in employment-based systems, where associated employment regulations and insurance arrangements are often focused primarily on employees. This situation might also be echoed for particular professions or sectors under different regulatory frameworks. The 'marginally employed' are similarly at risk under employment-based provisions, with exclusions likely to expand as labour markets become increasingly fragmented and the 'standard employment' model of permanent full-time work erodes. The measure captures requirements for a specified level of earnings or working hours (e.g., 20\%) to qualify for benefits (Dobrotić \& Blum, 2020 , p. 598). The scores are weighted to reward short qualifying periods more heavily, with the index overall providing a summative measure of access. Inclusion in this sense, while clearly a crucial component of social equality, may conflict with other dimensions of as we note below.

Panel B (Table 1) presents a gender equality index that seeks to capture the extent to which policy design is oriented towards the transformation of gendered patterns of paid and unpaid work. In line with the dual earner/dual caregiver model envisaged by writers such as Crompton (1999) and Gornick and Meyers (2008), which in turn echoes Fraser's (1997, p. 61) utopian vision of a "Universal Caregiver welfare state," this requires strategies that facilitate both mothers' labour force attachment and fathers' engagement in domestic and caring labour. A central element of this 'transformative' vision that has been incorporated into numerous gender equality indices is the availability and non-transferability of leave for fathers as critical influences on fathers' leave uptake (see, e.g., Ciccia \& Verloo, 2012; Dearing, 2016; Dobrotić \& Blum, 2020; Gornick \& Meyers, 2003, 2008; Haas \& Rostgaard, 2011; Javornik, 2014; Ray et al., 2010; Smith \& Williams, 2007). Such arrangements vary considerably between countries, with 'individual' entitlements for fathers sometimes fully or partially transferable to mothers and varying proportions of family entitlements reserved for fathers (see Koslowski, Blum, Dobrotić, Kaufman, \& Moss, 2020, p. 32). The first set of items in panel B represents this element in a scale (based on Dobrotić \& Blum, 2020, pp. 598, 600) that allocates 1 point for benefits that are primarily for mothers but may be transferred in specific circumstances, 2 for fully transferable family or individual entitlements, 3 for partially non-transferable $(<1 / 3)$ family or individual entitlements and 4 for arrangements with $\geq 1 / 3$ of the entitlement period reserved for fathers.

The second set of items in panel B represents another feature deemed crucial for fathers' leave uptake and widely incorporated in gender equality indices: well-paid leave, defined here as $\geq 66 \%$ of earnings (e.g., as in 
Koslowski et al., 2020, p. 44; Ray et al., 2010, p. 202). We are specifically concerned with the availability of well-paid non-transferable leave for fathers, given the importance of this combination for leave uptake (e.g., Castro-García \& Pazod-Moran, 2016). We also recognise that a very short leave period for fathers, even if well-paid, may provide minimal challenge to gendered patterns of work and care. We therefore allocate the highest score to well-paid non-transferable leave for at least six months (an ideal individual non-transferable leave period according to Gornick \& Meyers, 2008), with lower scores for shorter durations. The third set of items allocates scores for mothers' leave duration, inclusive of transferable and non-transferable leave as well as less than well-paid leave (given the likelihood that most available leave will be taken by mothers; see, e.g., Castro-García \& Pazod-Moran, 2016). While there is no consensus on optimal duration, risks such as entrenching maternalism with overly long leaves and exits from the labour market with very short periods are widely recognised, with a period of 6 to 12 months generally accepted as avoiding adverse consequences (see, e.g., Ciccia \& Verloo, 2012; Dearing, 2016; Javornik, 2014). We therefore allocate the highest score to this duration, with lower scores both above and below it. This third set is weighted less heavily than those for fathers' leave allocation and payment given the primacy accorded to the latter in the literature.

Incentives for fathers to access leave (most commonly additional leave if both parents use some) are weighted less heavily again but included in the index as potential levers for changing gendered patterns of leave-taking. Similarly, flexibility options may facilitate leave-taking and career continuity for both mothers and fathers, in particular by allowing breaks in usage (in two or more separate blocks) and part-time uptake (enabling a graduated return to work while still receiving benefits; see, e.g., Gornick \& Meyers, 2008; Haas \& Rostgaard, 2011).

The index is primarily oriented to the goal of triggering change in gendered divisions of paid and unpaid labour within couple families. Extending gender equality more broadly, including redressing inequalities between single mother and single father families, or between couple and single parent families, may require a different constellation of items (see Jou, Wong, Franken, Raub, \& Heymann, 2020). The composition of the index also raises questions about the complementarity of the three dimensions of social equality addressed in this article. Not only could lower requirements for employment continuity and labour force attachment (rewarded in the inclusion index) impede the dual earner/dual caregiver principle underpinning this gender equality index, there are also clear conflicts between this index and the one designed to represent redistribution, as outlined in the following.

Panel C (Table 1) presents a redistribution index, which represents a less frequently analysed dimension of social equality in relation to parental leave policies. Although redistribution is not a direct goal of parental leave policy, paid leave entitlements have the potential to be progressive or regressive in their impact. The extent to which they ameliorate or reproduce income inequalities among recipients depends in part on funding systems (with an earnings-based model tending to consolidate existing hierarchies) but importantly also on whether, and at what level, minimum and maximum payments are set. Under a generous minimum, low paid and marginally employed workers may receive higher payments than their usual wage during the benefit period, thus providing enhanced support for parenting. In the absence of empirical evidence on an optimally redistributive minimum payment, but with an aspiration for a minimum approaching the value of the average wage, we use a 'minimum payment' scale ranging from 0 to $>80 \%$ of the average wage for full-time employees. Based on quintiles to capture multiple levels of variation, it allocates scores from 0-5. For consistency, a quintile-based scale is also used (in reverse) for the maximum payment, starting from an upper limit of $200 \%$ of the average wage. This limit recognises Gornick and Meyers' (2008, pp. 324-325, 347) suggestion for a cap on paid leave entitlements of twice the national average wage, partly to contain costs but also as a constraint on highly regressive outcomes. A strongly redistributive policy design could, however, impose a lower maximum although again there is no empirical evidence for an optimal level. Given the relative importance of a high minimum (which would have the most impact on parental leave poverty) and the desirability of limiting only the highest earners rather than rewarding cost minimisation, we weight this item less heavily, allocating scores of $0-3$ across successively lower income bands, with the lowest set at $\leq 160 \%$ of the average wage for full-time workers. To preserve this balance between lower and upper limits, another means of restricting payments to high earners, an income test for access, is not included in the index.

An additional component of the redistribution index, accorded lower weighting again as its impact is less direct, is the taxation of benefits. Gornick and Meyers' $(2008$, p. 347) suggestion that, in the interests of progressivity, "a portion of high-income recipients' benefits could be taxed" is extended here to taxation of benefits for all recipients. While the impact of such a measure depends on the progressiveness of the income tax scale, it represents a principle consistent with redistribution.

Overall, the importance of this index lies in broadening the focus of social equality analyses of parental leave provisions. Although it requires further testing and refinement, it provides a starting point for such extension. It also draws attention to complementarities and conflicts with other dimensions of social equality-for example, the clear tension between limiting maximum payments here and the priority given to a high replacement wage in the interests of fathers' leave uptake in the gender equality index. These and related complexities 
will be drawn out in the ensuing comparison of Australia and Japan and in our conclusion.

\section{Comparing Paid Parental Leave Policies in Australia and Japan on Dimensions of Social Equality}

\subsection{Comparing Contexts and Outlining the Policies}

Despite contrasting institutional and cultural traditions, Australia and Japan display similarities as well as differences in welfare state characteristics and gendered work/family models. Australia, while classified among the 'liberal welfare states' (following Esping-Andersen, 1990), retains some vestiges of its history of what Castles (1989) depicted as "social protection by other means"-i.e., the high wages and social protections delivered through a strongly regulated wage-setting system bolstered by industry protection and restricted immigration. An important legacy of this history is the lack of a contributory social insurance scheme, which never gained political support in this context (see, e.g., Whitehouse, 2004). Japan, while exhibiting aspects of both liberal residualism and conservative occupational segmentation and familialism (Esping-Andersen, 1997), also has a history of social protection by other meansin this case through lifelong and full employment as forms of occupational welfare (Hwang, 2016). In contrast with Australia, it maintains a contributory employment insurance scheme. While economic liberalisation has reshaped welfare systems in both countries, this has led in different directions: Australia's system has become increasingly residual while Japan's has expanded, at least partly in response to demographic pressures (Hwang, 2016; Peng, 2002).

Within these welfare state configurations, both countries retain versions of a male breadwinner model. Australia's was institutionalised early in a needs-based family wage for white men and persists in partially modified form in a "maternal part-time work/care regime" (Whitehouse \& Brady, 2019, p. 258). Path dependencies associated with male breadwinner norms and liberal philosophies of governments have impeded Australia's move beyond maternalism in parental leave policy (Newsome, 2019), making it an extreme case even within Anglophone liberal welfare states, which-as Baird and O'Brien (2015) note-have made limited advancement on gender equality in leave policies. In Japan, strong male breadwinner norms have been deeply embedded in the lifetime employment and seniority wages system for men and the associated 'reproductive bargain' that allocates responsibility for family care to women (Gottfried, 2015). Although lifetime employment has been eroded to some extent, the male breadwinner model continues to be reflected in highly gender-segmented labour markets. Women are significantly overrepresented in peripheral insecure work (Gottfried \& O'Reilly, 2002) and high levels of commitment and long hours are demanded from those in the core labour market (Boling, 2015;
Brinton \& Mun, 2016). In this context, a significant proportion of women exit the labour market before the birth of a child (Nakazato, 2019, p. 106). Thus, while Japan has been able to extend its parental leave provisions, there are considerable pressures limiting uptake.

This contextual shaping of paid parental leave policy underpins a complex set of cross-national similarities and differences. A basic similarity is that both countries have 'parental' leave provisions consistent with the definition of "a care-related right available to both mothers and fathers" (Dobrotic \& Blum, 2020, p. 589). Both extend these entitlements to birth and adoptive parents, although Japan's provisions do not include the non-birth parent in same-sex couples. However, neither country offers the combination of maternity, paternity and parental leave that is commonly observed in Europe, at least not formally under those terms. In Australia, 'parental leave' is the term used for the individual entitlement to unpaid leave of 12 months for each parent, with 'parental leave pay' used for the payment available under the Paid Parental Leave scheme that commenced operation in 2011. The latter provides up to 18 weeks payment for the child's primary carer. Despite the genderneutral wording the payment is directed initially to the mother who may subsequently transfer all or part of it in specified circumstances. Since 2013, these arrangements have been supplemented with a 2 -week 'dad and partner pay' benefit solely for fathers/partners. This is equivalent to a short paternity leave payment although the term 'paternity' is avoided in the interests of signalling availability to same-sex couples. Both schemes are paid at a flat rate aligned with the national minimum wage, funded through general revenue.

In Japan, the two forms of paid leave available are termed maternity (literally 'pre-natal and post-natal') leave and parental (literally 'childcare') leave. The former provides the birth mother with benefits for up to six weeks prior to and eight weeks after the birth; the latter (which is the focus of our analysis) is an individual 12-month entitlement available to both parents for use within the first 12 months of the child's life (a period that can be extended to a maximum of 14 months from the child's birth if the father takes some leave). While there is no paternity leave as such, the provision to allow fathers to take a portion of their parental leave entitlement during the first eight weeks after the birth can be seen as allowing a period of leave for fathers commensurate with a mother's 'maternity leave.' The parental leave scheme is funded through employment insurance, providing earnings-based payments set at $67 \%$ for the first 180 days of parental leave, then $50 \%$ for the remainder.

Further details on the policies under investigation are drawn out in the analysis that follows. We focus on policy design differences relating to inclusion, gender equality and redistribution, reflecting on the influence of the contextual factors we have outlined. 


\subsection{Comparing Policies on Inclusion, Gender Equality and Redistribution}

Scores for Australia and Japan on each of the items that comprise the indices in Table 1 are given in Table A1 (see Supplementary File). Figure 1 presents the index scores as percentages, consistent with our depiction of the indices as representing equally important dimensions of social equality. As Figure 1 shows, the countries performed very differently on the three indices, most markedly on gender equality where Japan recorded a full score while Australia only achieved $21 \%$. However, Australia scored more highly than Japan on the other two indices, particularly on redistribution. These differences are explored in the sub-sections below.

\subsubsection{Inclusion}

The contrast shown in Figure 1, with Australia scoring $67 \%$ and Japan $42 \%$ in the inclusion index, is due to variation on two components of the index: the employment period required to qualify for benefits and the inclusion of self-employed workers (for country scores on the items discussed here and in the following sub-sections see Table A1 in the Supplementary File). Examination of these differences, including some more subtle contrasts not captured by the index, suggests where barriers to inclusion lie in spite of attempts in both countries to develop broadly inclusive measures.

Australia's marginally higher score on the 'employment period needed to qualify for benefits' criterion reflects the flexibility of its work test, which requires employment during 10 of the 13 months prior to the birth, for at least 330 hours (equivalent to around one day per week) in that 10-month period (Whitehouse, Baird, \& Baxter, 2020, p. 83). The test was explicitly designed to be more inclusive than Australia's unpaid parental leave, which (as an entitlement located in the industrial relations regulatory framework) requires 12 months with the same employer prior to access. Funding of the payment scheme through general revenue, while introducing complexities by locating leave and payment in different regulatory arenas, allowed the flexibility to expand eligibility in ways that acknowledged the likely irregularity of women's employment patterns. In Japan, eligibility requires a minimum of 12 months insurance contributions over the past two years, which places it in the more restrictive category of $\geq 12$ months of employment for qualification. However, the benefit is available to employees with irregular working patterns, the lower limit being a work history of 11 or more days in each of those 12 months (Nakazato, Nishimura, \& Takezawa, 2020, p. 356).

Both countries score points for allowing interruptions and changes of employer during the qualifying period for access to payments. In Australia, inclusiveness has been further widened recently with an extension of the permitted period of interruption between work days from eight to 12 weeks (Whitehouse et al., 2020, p. 88).

Turning to the criteria under 'different employment forms and sectors,' Japan's exclusion of the selfemployed reflects the scope of its employment insurance system, but neither country excludes particular professions or sectors, or those below a specified earnings level. As we have outlined above, both impose access limits based on working time: the equivalent of around one day per week in Australia and 11 days per month in Japan during the qualifying periods. Although beyond our focus on statutory provisions, we also note that employers in Japan are not obliged to have employees working $<20$ hours/week covered by employment insurance, hence many of these workers may be ineligible for benefits. For employees on fixed-term contracts (i.e., those with a specified end date), there are no explicit restrictions in Australia other than to meet the work test, which may still exclude some depending on the timing

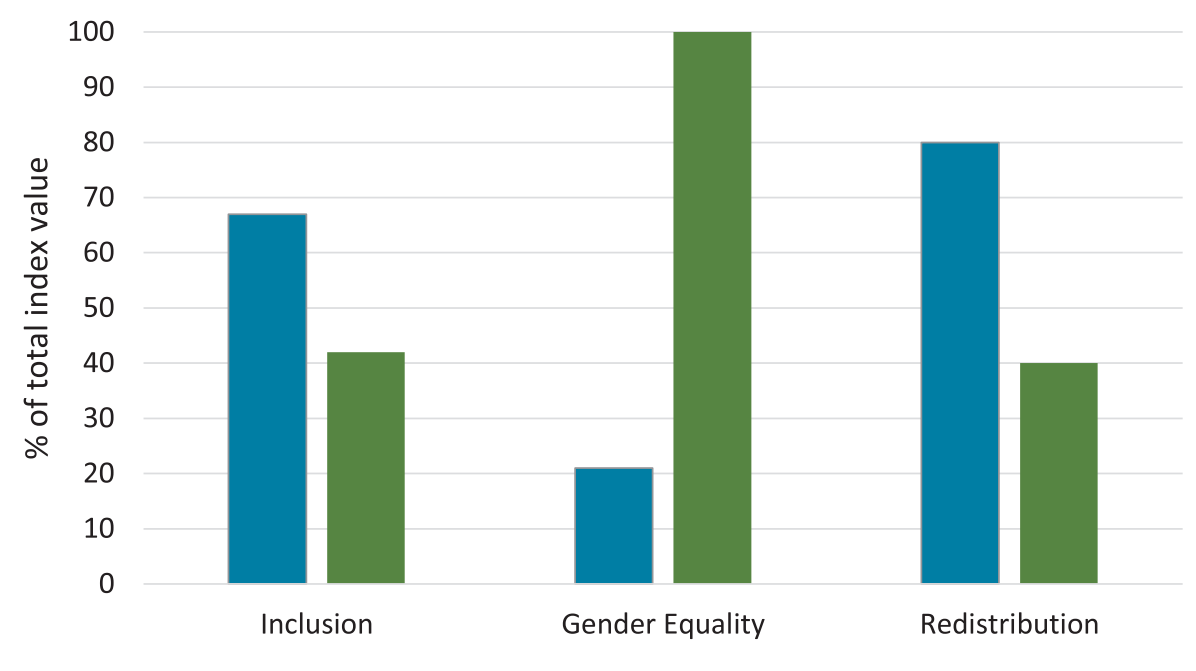

- Australia uapan

Figure 1. Inclusion, gender equality and redistribution in paid parental leave policy, Australia and Japan, 2020. 
and duration of the employment term. In Japan, fixedterm employees can access leave (and thus payment, which cannot be received in the absence of the leave entitlement) provided the employee has been with the employer continuously for 12 months and it is not obvious that the contract will end before the child reaches 18 months and not be extended (Nakazato et al., 2020, p. 356). While differences in the classification of employment types in national statistics prevent meaningful comparison between the countries on the implications of these restrictions, we note that both countries have highly-divided labour markets, with a persistently high proportion of employees in non-standard ('non-regular' in Japan) employment (Cooke \& Jiang, 2017; Whitehouse \& Brady, 2019, p. 260).

Overall, differences in inclusiveness between the countries are at least partly attributable to funding arrangements, with Japan's employment insurance model requiring a higher level of workforce engagement than Australia's government-funded system. Additionally, while both countries have marked labour market divisions, the distinction between regular and non-regular status is particularly strong in Japan, with non-regular (including part-time) work providing limited access to employment and social welfare benefits (Boling, 2015, p. 152). In both cases there is a risk of the further erosion of access with increases in marginal forms of employment. While these pressures, and the current less than optimal performance of both countries on this index, raise concerns for inclusion, there are also questions over how inclusive employmentbased systems can become without eroding other dimensions of social equality (an issue we return to in the conclusion).

\subsubsection{Gender Equality}

As Figure 1 shows, the countries differ most on the gender equality index, with Australia scoring only $21 \%$ compared with Japan's $100 \%$. The discrepancy is greatest on the first two items. Australia's low score on 'gendered allocation and transferability of leave' reflects its direction of parental leave payments primarily to mothers. While there are provisions for its transfer to another carer in specified circumstances (see Whitehouse et al., 2020, pp. 82-83), the initial recipient is the mother. In contrast, Japan's fully non-transferable individual entitlements place it at the top of this scale.

On 'duration of well-paid non-transferable leave for fathers,' Australia scores 0 , with none of the parental leave payment entitlement well-paid or reserved for fathers. While the limited benefit available under 'dad and partner pay' is non-transferable, it is in effect a short paternity rather than a parental leave entitlement and is not well-paid. In contrast, Japan receives the maximum score for its 12-month individual non-transferable entitlement for fathers paid at $67 \%$ of previous earnings for the first 180 days. Although capped, the maximum monthly benefit for this period is $94 \%$ of the average monthly wage (based on 2019 figures).

Turning to 'duration of leave for mothers,' Australia scores one point for its 18-week entitlement but Japan scores 2 for the optimal category of ' $6-12$ months.' While there is provision for an extension of parental leave in Japan when a childcare place is not availablecircumstances in which Japan would score only 1 point (for $>12$ but $<24$ months)-we use the general rule rather than the exception for scoring.

Only Japan scores a point for 'incentives for fathers' uptake.' In 2010, an additional two months of leave was provided, extending the permissible leave-taking period from 12 to 14 months after the child's birth if the father takes at least two months' leave, or by a lesser amount if the father takes $<2$ months (this does not, however, change the 12-months maximum for each parent.) On the 'flexibility' items, Australia scores a half-point for a recently introduced provision that allows the 18-week entitlement to be split into an initial 12-week block to be used in the first 12 months, with the remainder accessible any time during the first two years (for further details see Whitehouse et al., 2020, p. 89). Both of the listed flexibility items are available in Japan, where, since 2010, fathers can take some of their leave entitlement during the first eight weeks following a birth and a second block at a later stage within the permitted period of up to 14 months after the child's birth (Nakazato et al., 2020, p. 356). Mothers may also take a break between their maternity leave and parental leave, but each of those entitlements must be taken in a continuous block. Additionally, in Japan benefit recipients may return to work part-time for up to 80 hours during a monthly payment period, in which case the benefit is adjusted so that the sum of their earnings and benefit does not exceed $80 \%$ of their earnings prior to taking leave. These subtleties in comparison underline the complexity of national policy designs and the varying ways in which incremental changes can extend the capacity for gender equality, at least at the margins.

More fundamental changes are inevitably constrained by welfare state and gender norms, only rarely gaining political traction. Australia's poor overall performance on this index reflects path dependencies in funding arrangements and a residual and maternalist welfare state. Japan's capacity to innovate stems from the confluence of systemic factors (specifically the suitability of individual entitlements within an employment insurance system and the contributory funding arrangements that reduced the direct cost to government of successive increases towards the current generous benefit levels) and the expansion of its welfare state from the 1990s in response to "gender and demographic imperatives" (Peng, 2002, p. 412). These imperatives included the pressures of women's activism and the increasing attention to gender equality in public discourse following passage of the Basic Act for a Gender Equal Society in 1999 as well as persistent concerns over falling fertility rates 
(see Nakazato, 2019). The frequency of references to fathers' low take-up rates in parliamentary discussions in the early 2000s, and the policy amendments subsequently designed to redress this problem, illustrate the political salience of the issue over a sustained period.

An important caveat is that, in spite of generous gender-egalitarian provisions, take-up rates among fathers are very low in Japan. A survey of private enterprises in 2019 showed that $7.48 \%$ of male workers whose spouse had given birth between 1 October 2017 and 30 September 2018 had started or applied for paid parental leave by 1 October 2019 (Ministry of Health, Labour and Welfare, 2020, p. 22). Without change in the expectation of high levels of commitment and long working hours for full-time permanent workers that remain persistent features of Japanese corporate culture and shape managers' attitudes towards parental leave (see Brinton \& Mun, 2016), this disjunction between gender egalitarian design and gender equality in practice is likely to persist (the different model of paid parental leave in Australia and lack of relevant statistics prevent comparison of the two countries on uptake levels).

Overall, differences between the countries on the gender equality index are again significantly shaped by the contrasting funding systems. Japan's contributory social insurance scheme (seen in the previous section as partially constraining the flexibility for widening inclusiveness) enables higher payments than those possible within Australia's general revenue arrangements. However, this contrast in payment systems has a different set of implications for our third index.

\subsubsection{Redistribution}

As indicated in Figure 1, Australia ranks considerably higher than Japan on the redistribution index, scoring $80 \%$ compared with Japan's $40 \%$. Differences on the 'minimum payment' component reflect the contrast between Australia's flat-rate, and Japan's earnings-based, payment systems. Set at the national minimum wage, Australia's arrangements provide recipients with $44 \%$ of the full-time average weekly wage (based on 2019 figures for consistency of comparison between the two countries). The benefit is paid at the full-time rate, thus providing some recipients with higher payments during their leave period than in their pre-leave employment. In Japan, while there is a minimum monthly payment, it is set at a comparatively low level, varying in 2019 between $15 \%$ of average monthly earnings for full-time employees (for the first 180 days) and $12 \%$ (for the remainder of the entitlement). This wide discrepancy between the countries highlights the comparatively regressive effect of earnings-based funding arrangements, with Australia's high minimum wage further widening the gap between the two countries.

On the 'maximum payment/cap' item, both countries fall into the $\leq 160 \%$ average wage category, hence both receive full scores. Under Australia's flat-rate system, the maximum is the same as the minimum $(44 \%$ of the average wage), while Japan's maximum payment (represented by a cap on its earnings-based benefit) is equivalent to $94 \%$ of the average wage for full-time employees for the first 180 days of the entitlement, reducing to $70 \%$ for the remainder. Although these are very different levels (and Australia also imposes an income test on access which is not captured in the index), even Japan's higher maximum is well below the cut-offs applied here for reduced scores due to 'regressive' levels of maximum payments.

On the final component of this index, 'payments taxable,' only Australia gains points. Taxation of benefits was adopted in Australia both as consistent with redistributive goals and as a means of distinguishing the benefit from a welfare payment (Productivity Commission, 2009, p. 27). In combination with a flat-rate payment, which was a clear disadvantage for the gender equality index but is advantageous here, this produces a wide gap in overall scores between the two countries. While Japan places caps on high payments, it also sets very low minimum payments, thus significantly limiting the capacity for redistributive benefits.

\section{Conclusion}

Australia and Japan represent distinctive manifestations of selective employment-based paid parental leave entitlement systems with differing capacities for advancing social equality within their policy designs. This is clearly illustrated in their disparities both within and between the three indices used in this analysis. While their provisions are continually being modified through incremental adjustments, these are unlikely to erode the main dissimilarities between them or produce optimal outcomes in either country in the near future. Although Japan's innovations on gender equality (which underpin the starkest difference between the two countries) are a reminder that radical policy changes can occur, they also indicate that complementary changes in social and labour market norms are essential if gender egalitarian policy design is to be translated into gender equality in outcomes.

Among the lessons from our comparison is the importance of funding systems as drivers of policy difference. A contributory employment insurance scheme has distinct advantages for the generosity of payments: Australia's general revenue funding model renders anything other than a flat-rate payment politically contentious, while Japan's insurance model presented less of a barrier to claims in that country for more generous entitlements. However, there is no consistent 'winner' between insurance-based and general revenuebased systems across the three dimensions of social equality under examination here. While gender equality is enhanced by the more generous payments available under an insurance scheme, Australia's higher score in relation to inclusion at least partly reflects its 
government-funded benefit scheme which allowed for less restrictive eligibility criteria than those applying to its unpaid leave benefit under employment regulation. Although extensions of coverage are not impossible under a social insurance scheme, the requirement for contributions in return for benefits may place stronger limits on the extent to which eligibility can be expanded. Moreover, general revenue funding (to the extent that it predisposes to modest flat-rate benefits) has the capacity to enhance redistribution-essentially by avoiding the inbuilt regressivity in earnings-based systems that are more likely to be supported by insurance funding. As Blofield and Martínez Franzoni (2015) argue, contributory systems benefit higher earners and standard fulltime workers disproportionately.

These tensions between our three dimensions highlight the complexities of social equality as a normative vision, raising questions over whether explicit trade-offs are needed between them. One strategy could be to prioritise building on complementary features. For example, high minimum benefits potentially enhance both class and gender equality through supporting the (disproportionately female) lower paid and marginally employed. Other tensions, such as the tendency of looser eligibility criteria to undermine the dual earner/dual caregiver family model that underpins gender equality goals, may require calculated trade-offs, although the measures noted in the following paragraph could significantly lessen this conflict.

Ultimately a more socially egalitarian context is needed to enable the translation of social equality in policy design into egalitarian outcomes-as Moss and Deven (1999) have perceptively noted in relation to gender equality. Rather than a disabling circularity, this observation underlines the importance of a complementary set of social equality policies, both in response to widening inequality generally (e.g., through increasingly progressive taxation) and particularly in relation to deepening labour market divisions (through employment regulation). Similarly, narrowing the gender pay gap would reduce the tension between conflicting pressures for high payments to encourage fathers' leave uptake and limiting regressive distribution of benefits. A more egalitarian labour market would reduce the likelihood that social equality provisions in policy design fail to translate into equality in outcomes or exacerbate tensions between gender equality and inclusion. While this broader regulatory framework is not on the agenda in Australia or Japan, it is the context in which employmentbased paid parental leave policies have the greatest potential to contribute to a more egalitarian future.

\section{Acknowledgments}

The authors thank the editors of the thematic issue and the anonymous referees for valuable feedback on earlier drafts of this article. Part of this work was supported by JSPS KAKENHI Grant Number JP18K02019.

\section{Conflict of Interests}

The authors declare no conflict of interests.

\section{Supplementary Material}

Supplementary material for this article is available online in the format provided by the author (unedited).

\section{References}

Baird, M., \& O'Brien, M. (2015). Dynamics of parental leave in Anglophone countries: The paradox of state expansion in liberal welfare regimes. Community, Work \& Family, 18(2), 198-217.

Blofield, M., \& Martínez Franzoni, J. M. (2015). Maternalism, co-responsibility, and social equity: A typology of work-family policies. Social Politics, 22(1), 38-59.

Boling, P. (2015). The politics of work-family policies: Comparing Japan, France, Germany, and the United States. Cambridge: Cambridge University Press.

Brinton, M., \& Mun, H. (2016). Between state and family: Managers' implementation and evaluation of parental leave policies in Japan. Socio-Economic Review, 14(2), 257-281.

Castles, F. (1989). Social protection by other means: Australia's strategy of coping with external vulnerability. In F. Castles (Ed.), The comparative history of public policy (pp. 16-37). Cambridge: Polity Press.

Castro-García, C., \& Pazod-Moran, M. (2016). Parental leave policy and gender equality in Europe. Feminist Economics, 22(3), 51-73.

Ciccia, R., \& Verloo, M. (2012). Parental leave regulations and the persistence of the male breadwinner model: Using fuzzy-set ideal type analysis to assess gender equality in an enlarged Europe. Journal of European Social Policy, 22(5), 507-528.

Cooke, F. L., \& Jiang, Y. (2017). The growth of nonstandard employment in Japan and South Korea: The role of institutional actors and impact on workers and the labour market. Asia Pacific Journal of Human Resources, 55(2), 155-176.

Crompton, R. (1999). Restructuring gender relations and employment: The decline of the male breadwinner. New York, NY: Oxford University Press.

Dearing, H. (2016). Gender equality in the division of work: How to assess European leave policies regarding their compliance with an ideal leave model. Journal of European Social Policy, 26(3), 234-247.

Dobrotić, I., \& Blum, S. (2020). Inclusiveness of parental leave benefits in twenty-one European countries: Measuring social and gender inequalities in leave eligibility. Social Politics, 27(3), 588-614.

Esping-Andersen, G. (1990). The three worlds of welfare capitalism. Cambridge: Polity Press.

Esping-Andersen, G. (1997). Hybrid or unique? The Japanese welfare state between Europe and America. Journal of European Social Policy, 7(3), 179-189. 
Fraser, N. (1997). Justice interruptus: Critical reflections on the "postsocialist" condition. London and New York, NY: Routledge.

Ghysels, J., \& Van Lancker, W. (2011). The unequal benefits of activation: An analysis of the social distribution of family policy among families with young children. Journal of European Social Policy, 21(5), 472-485.

Gornick, J., \& Meyers, M. (2003). Families that work: Policies for reconciling parenthood and employment. New York, NY: Russell Sage Foundation.

Gornick, J., \& Meyers, M. (2008). Creating gender egalitarian societies: An agenda for reform. Politics \& Society, 36(3), 313-349.

Gottfried, H. (2015). The reproductive bargain: Deciphering the enigma of Japanese capitalism. Leiden: Brill Academic Publishing.

Gottfried, H., \& O'Reilly, J. (2002). Reregulating breadwinner models in socially conservative welfare systems: Comparing Germany and Japan. Social Politics, 9(1), 29-59.

Haas, L., \& Rostgaard, T. (2011). Fathers' rights to paid parental leave in the Nordic countries: Consequences for the gendered division of leave. Community, Work \& Family, 14(2), 177-195.

Hegewisch, A., \& Gornick, J. (2011). The impact of workfamily policies on women's employment: A review of research from OECD countries. Community, Work \& Family, 14(2), 119-138.

Howcroft, D., \& Rubery, J. (2019). 'Bias in, bias out': Gender equality and the future of work debate. Labour \& Industry: A Journal of the Social and Economic Relations of Work, 29(2), 213-227.

Hwang, G.-J. (2016). Common paths, divergent patterns: The social protection by other means approach in Australia and Japan. International Journal of Social Welfare, 25, 36-46.

Javornik, J. (2014). Measuring state de-familialism: Contesting post-socialism exceptionalism. Journal of European Social Policy, 24(3), 240-257.

Jou, J., Wong, E., Franken, D., Raub, A., \& Heymann, J. (2020). Paid parental leave policies for singleparent households: An examination of legislative approaches in 34 OECD countries. Community, Work \& Family, 23(2), 184-200.

Koslowski, A., Blum, S., Dobrotić, I., Kaufman, G., \& Moss, P. (Eds.). (2020). International review of leave policies and related research 2020. International Network on Leave Policies \& Research. Retrieved from http://www.leavenetwork.org/lp_and_r_reports

Leitner, S. (2003). Varieties of familialism: The caring function of the family in comparative perspective. European Societies, 5(4), 353-375.

Lewis, J. (2001). The decline of the male-breadwinner model: Implications for work and care. Social Politics, 8(2), 152-169.

Mathieu, S. (2016). From the defamilialization to the "demotherization" of care work. Social Politics, 23(4), 567-591.
McKay, L., Mathieu, S., \& Doucet, A. (2016). Parentalleave rich and parental-leave poor: Inequality in Canadian labour market based leave policies. Journal of Industrial Relations, 58(4), 543-562.

Ministry of Health, Labour and Welfare. (2020). Reiwa Ganendo Koyō Kintō Kihon Chōsa Kekka no Gaiyō [Summary report of the results of the 2019 survey of gender equality in employment management]. Tokyo: Ministry of Health, Labour and Welfare. Retrieved from https://www.mhlw.go.jp/toukei/list/ dl/71-r01/03.pdf

Moss, P., \& Deven, F. (Eds.). (1999). Parental leave; progress or pitfall? Brussels: Netherlands Interuniversity Demographic Institute and Population and Family Study Centre Publications.

Nakazato, H. (2019). Japan: Leave policy and attempts to increase fathers' take-up. In P. Moss, A.-Z. Duvander, \& A. Koslowski (Eds.), Parental leave and beyond: Recent developments, current issues, future directions (pp. 91-109). Bristol: Policy Press.

Nakazato, H., Nishimura, J., \& Takezawa, J. (2020). Japan country note. In A. Koslowski, S. Blum, I. Dobrotić, G. Kaufmann, \& P. Moss (Eds.), International review of leave policies and research 2020 (pp. 353-364). Hagen: Fakultät für Kultur- und Sozialwissen-schaften. Retrieved from http://www. leavenetwork.org/lp_and_r_reports

Newsome, L. (2019). Gender and citizenship in Australia: Government approaches to paid parental leave policy 1996-2017. Social Politics: International Studies in Gender, State \& Society. https://doi.org/10.1093/ $\mathrm{sp} / \mathrm{jxz029}$

O'Brien, M. (2009). Fathers, parental leave policies, and infant quality of life: International perspectives and policy impact. Annals of the American Academy of Political and Social Science, 624(1), 190-213.

Palier, B. (2018). The politics of social risks and social protection in digitalised economies. In M. Neufeind, F. Ranft, \& J. O'Reilly (Eds.), Work in the digital age: Challenges of the fourth industrial revolution (pp. 247-258). London: Rowman and Littlefield International.

Peng, I. (2002). Social care in crisis: Gender, demography, and welfare state restructuring in Japan. Social Politics: International Studies in Gender, State \& Society, 9(3), 411-443.

Productivity Commission. (2009). Paid parental leave: Support for parents with newborn children. Canberra: Australian Government.

Ray, R., Gornick, J., \& Schmitt, J. (2010). Who cares? Assessing generosity and gender equality in parental leave policy designs in 21 countries. Journal of European Social Policy, 20(3), 196-216.

Smith, A., \& Williams, D. (2007). Father-friendly legislation and paternal time across Western Europe. Journal of Comparative Policy Analysis, 9(2), 175-192.

Tarrow, S. (2010). The strategy of paired comparison: Towards a theory of practice. Comparative Political 
Studies, 43 (2), 230-259.

Whitehouse, G. (2004). From family wage to parental leave: The changing relationship between arbitration and the family. The Journal of Industrial Relations, 46(4), 400-412.

Whitehouse, G., Baird, M., \& Baxter, J. (2020). Australia country note. In A. Koslowski, S. Blum, I. Dobrotić, G. Kaufman, \& P. Moss (Eds.), International review of leave policies and research 2020 (pp.
78-93). Hagen: Fakultät für Kultur- und Sozialwissenschaften. Retrieved from http://www.leavenetwork. org/lp_and_r_reports

Whitehouse, G., \& Brady, M. (2019). Parental leave, social inequalities and the future of work: Possibilities and constraints within the Australian policy framework. Labour \& Industry: A Journal of the Social and Economic Relations of Work, 29(3), 257-272.

\section{About the Authors}

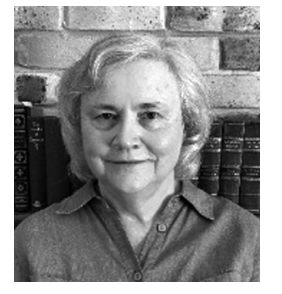

Gillian Whitehouse is Professor Emerita at the School of Political Science and International Studies, University of Queensland, Australia. Her research focuses on the influence of institutional and policy frameworks on employment and social inequalities. Her recent publications include "Equal Pay for Work of Equal Value, Wage-Setting and the Gender Pay Gap," a co-edited special issue of the Journal of Industrial Relations on gender pay equality in Australia, New Zealand and East Asia.

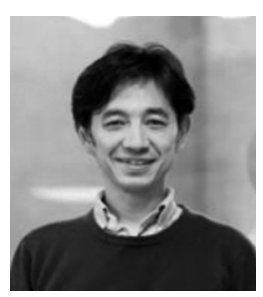

Hideki Nakazato is Professor at the Department of Sociology, Konan University, Japan. His key research interests are work-life balance, parenting and gender roles. One central area of study has been parental leave policies and fathers' take up of the leave. His recent international publications include "Japan: Leave Policy and Attempts to Increase Fathers' Take-Up" in Parental Leave and Beyond: Recent Developments, Current Issues, Future Directions (edited by P. Moss, A.-Z. Duvander and A. Koslowski). 